\title{
PROGNOSTIC VALUE OF KIDNEY FUNCTION PARAMETERS IN PATIENTS WITH CHRONIC HEART FAILURE AND LEFT VENTRICULAR REDUCED EJECTION FRACTION
}

\author{
Anna Dudnik \\ Department of heart failure NSC \\ National Scientific Center "M.D. Strazhesko Institute of Cardiology" \\ 5 Narodnoho Opolchennya str., Kyiv, Ukraine, 02000 \\ dudnikanya77@gmail.com \\ Alina Liashenko \\ Department of heart failure \\ National Scientific Center "M. D. Strazhesko Institute of Cardiology" \\ 5 Narodnoho Opolchennya str., Kyiv, Ukraine, 02000 \\ lyashenko2007@ukr.net \\ Leonid Voronkov \\ Department of heart failure \\ National Scientific Center "M.D. Strazhesko Institute of Cardiology" \\ 5 Narodnoho Opolchennya str., Kyiv, Ukraine, 02000 \\ lgvoronkov@gmail.com
}

\footnotetext{
Abstract

Chronic heart failure (CHF) is a complex clinical syndrome characterized by progressive course, unsatisfactory quality of life, poor prognosis and high incidence of concomitant renal dysfunction (RD).

The aim of our work was to study the prognostic value of a number of renal function indicators in patients with CHF and a reduced left ventricular ejection fraction (LVEF).

Materials and methods. 134 patients with stable CHF and reduced $(<40 \%)$ LVEF, II-IVNYHA class were examined. Patients were divided into two groups according to the level of GFR: the first group of GFR $<60 \mathrm{ml} / \mathrm{min}$. $/ 1.73 \mathrm{~m}^{2}$, the second GFR $\geq 60 \mathrm{ml} / \mathrm{min} . / 1.73 \mathrm{~m}^{2}$. The average follow-up period was 13.4 months, the maximum was $27.5 \mathrm{months}$.

Results. In 53 patients RD was detected (glomerular filtration rate was $<60 \mathrm{ml} / \mathrm{min} / 1.73 \mathrm{~m}^{2}$ ), which was $39.5 \%$. Patients of both groups did not differ in their main hemodynamic parameters, left ventricular ejection fraction, and pharmacotherapy structure, but were older in age and heavier clinically. After the analysis of survival curves of patients depending on GFR, a group of patients with RD had a significantly worse survival prognosis compared to a group without RD. After adjusting the groups by age and NYHA class, the indicated difference was maintained. The subjects were divided according to median levels: blood urea nitrogen, blood urea nitrogen/creatinine ratio, microalbuminuria, albumin / creatinine ratio in urine.

The long-term survival of the formed groups was analyzed. The level of blood urea nitrogen did not significantly influence the prognosis of patients with CHF and reduced LVEF. At the same time, when the groups were divided, depending on the median value of the blood urea nitrogen/creatinine ratio, there was a significantly higher risk of fatal outcome in the group with lower indices. The level of MAU did not significantly affect the survival of patients. In addition, a comparison of the survival of patients with higher and lower values of the albumin/creatinine ratio in the urine revealed a significantly higher risk of death in patients with higher values.

Conclusions:

1. The presence of $\mathrm{RD}\left(\mathrm{GFR}<60 \mathrm{ml} / \mathrm{min} / 1.73 \mathrm{~m}^{2}\right)$ is observed in $39.5 \%$ of patients with CHF and reduced LVEF and is associated with their worst long-term survival.

2. The BUN and MAU do not have sufficient predictive information about the forecast of long-term survival of the above category of patients.

3. At the same time, the values of the BUN/ Creatinine ratio $<24.5$ and the $\mathrm{ACR}>12.7$ indicate patients with $\mathrm{CHF}$ who have a higher long-term risk of death.

Keywords: chronic heart failure, reduced left ventricular ejection fraction, glomerular filtration rate, blood urea nitrogen, microalbuminuria. 


\section{Introduction}

Chronic heart failure (CHF) is a complex clinical syndrome, characterized by a progressive course, unsatisfactory quality of life and a worse prognosis [1, 2]. The risk of death within one year in patients with CHF, even with modern methods of their treatment, is from 6.9 to $15.6 \%$ according to different data [3]. CHF is characterized by a high incidence of concomitant pathology, among which renal dysfunction (RD) occupies one of the leading positions.

According to the results of various studies, the number of patients with CHF and RD varies from 32 to $66 \%[4,5]$. The combination of cardiac and renal pathology is considered within the cardio-renal syndrome [6] and is discussed in the context of common factors of pathogenesis and mutual influence on the course of CHF, drug therapy, and a prognosis [7]. The glomerular filtration rate (GFR) is a universal marker for assessing renal function, with a decrease of GFR below $60 \mathrm{ml} / \mathrm{min} / 1.73 \mathrm{~m}^{2}$ being considered as the presence of RD [8]. It is known that a decrease of GFR in patients with $\mathrm{CHF}$ has a greater prognostic value than of the left ventricle ejection fraction (LVEF) [9]. One of the most important parameters of the renal function is blood urea nitrogen (BUN), which, according to a number of researchers, can serve as an indirect marker of neurohumoral activation [10]. Non-ligand diagnostic markers of kidney condition include microalbuminuria (MAU), and albumin/creatinine ratio (ACR), which makes it possible to level the variability of albumin excretion fluctuations due to drinking regimen and hydration [11]. MAU is a proven independent predictor of cardiovascular complications in patients with hypertension [12], but data on its prognostic value with stable CHF are almost absent.

\section{Aim of the research}

Taking into account the above, and taking into account the expediency of searching for new markers that can help improve the quality of dispensary observation of such patients, the aim of our work was to study the prognostic value of a number of renal function indicators in patients with $\mathrm{CHF}$ and reduced left ventricular ejection fraction (LVEF).

\section{Materials and methods}

Patients were observed on the basis of the heart failure department in National Scientific Center "M.D. Strazhesko Institute of Cardiology" from 2016 to 2018.

134 patients with stable CHF and $<40 \%$ LVEF, NYHA class II-IV, whose median age was $59.5(54 ; 68)$ years were examined. The criteria for inclusion in the study were:

1) the age of patients from 18 to 75 years;

2) CHF caused by ischemic heart disease (including in combination with $\mathrm{AH}$ ) or dilated cardiomyopathy;

3) $\mathrm{LVEF}<40 \%$; (NYHA).

4) II-IV functional class according to the criteria of the New York Heart Association

The criteria for exclusion were:

1) age over 75 years;

2) $\mathrm{LVEF}>40 \%$;

3) $\mathrm{GFR} \leq 30 \mathrm{ml} / \mathrm{min} . / 1.73 \mathrm{~m}^{2}$;

4) acute forms of ischemic heart disease;

5) signs of congestion;

6) acute infectious diseases;

7) acute and chronic diseases of the urinary tract and chronic organic kidney damage (glomerulonephritis, pyelonephritis), nephrotic syndrome;

8) unsatisfactory adherence to treatment;

9) diabetes mellitus type I;

10) acquired valvular heart disease;

11) inflammatory and restrictive lesions of the myocardium;

12) oncology;

13) acute disorders of cerebral circulation; 
14) availability of artificial pacemakers, cardio-resynchronizing therapy;

15) severe anemia $(\mathrm{Hb}<80 \mathrm{~g} / \mathrm{l})$.

All patients underwent general clinical examination, routine 12-lead ECG and ultrasound examination of the heart by a standard procedure. The creatinine concentration was determined by the kinetic method of Jaffe without deproteinization, the level of GFR was estimated using the CKD-EPI equation [8]. Determination of the urea concentration was carried out by the urease method, the appropriate recalculation factor was used to determine urea nitrogen: urea $(\mathrm{mmol} / \mathrm{l}) \times$ $\times 0.467=$ blood urea nitrogen $(\mathrm{mmol} / \mathrm{l})$ [13]. The determination of MAU was carried out using the turbidimetric method [14]. The MAU criteria is $29-300 \mathrm{mg}$ of protein in urine per day.

The patients were treated with standard inhibitors of the renin-aldosterone system (RAS), diuretics, beta-blockers and antagonists of mineralocorticoid receptors (AMR) in accordance with the current standards of the Association of Cardiologists of Ukraine for the diagnosis and treatment of chronic heart failure [15]. Statistical processing of information was carried out using the "STATISTICA" software package v. 6.0. Absolute and relative frequencies (n, \%) were used to describe the qualitative characteristics, for the quantitative indices - the median, upper and lower quartiles. The reliability of the differences in the parameters was verified using the Mann-Whitney test, for qualitative ones, using the Pearson $\chi^{2}$ criterion, with the construction of conjugacy tables. The difference was considered reliable at a value of $\mathrm{p}<0.05$. To find the connection between the phenomena, the Spearman rank correlation coefficient was used. To evaluate the survival rate, a log rank test was used to construct the Kaplan-Meier curves.

\section{Results}

Patients included in the study in stable CHF with a reduced LVEF were divided into two groups according to the level of GFR: the first group of GFR $<60 \mathrm{ml} / \mathrm{min} / 1.73 \mathrm{~m}^{2}$, the second $\mathrm{GFR} \geq 60 \mathrm{ml} / \mathrm{min} / 1.73 \mathrm{~m}^{2}$. In 53 patients RD was detected, which consisted $39.5 \%$. At the first stage, patients were compared by age, NYHA class and hemodynamic parameters, and the structure of pharmacotherapy, depending on the presence of RD (Table 1). Patients of both groups did not differ in hemodynamic parameters such as heart rate (HR), systolic blood pressure (SBP), LVEF and were comparable in the structure of the prescribed treatment. At the same time, patients with RD were older and characterized, in contrast to patients without RD, by a predominance of higher (III-IV) classes according to NYHA (Table 1).

\section{Table 1}

Comparability of groups of patients with RD and without RD according to age, indicators of hemodynamics, NYHA class and the structure of pharmacotherapy

\begin{tabular}{|c|c|c|c|}
\hline Indicators & $\underset{(\mathrm{n}=53)}{\mathrm{GFR}<60 \mathrm{ml} / \mathrm{min} / 1.73 \mathrm{~m}^{2}}$ & $\underset{(n=81)}{G F R \geq 60 \mathrm{ml} / \mathrm{min} / 1.73 \mathrm{~m}^{2}}$ & $\mathbf{P}$ \\
\hline Age, (Me (LQ;UQ) & $67(63 ; 70)$ & $58(45 ; 76.4)$ & $<0.001$ \\
\hline HR, bpm (Me (LQ;UQ) & $76(70 ; 82)$ & $72(66 ; 80)$ & 0.357 \\
\hline SBP, mm Hg (Me (LQ;UQ) & $110(100 ; 120)$ & $110(110 ; 120)$ & 0.286 \\
\hline LVEF, \% (Me (LQ;UQ) & $26(21 ; 33)$ & $29(22 ; 35)$ & 0.443 \\
\hline NYHA II (n, \%) & $920 \%$ & $3680 \%$ & $<0.010$ \\
\hline NYHA III-IV (n, \%) & $4483 \%$ & $4556 \%$ & 0.009 \\
\hline Diuretics (and) (n, \%) & $5196 \%$ & $7693 \%$ & 0.541 \\
\hline ACE inhibitors or ARB II (n, \%) & $2649 \%$ & $5163 \%$ & 0.111 \\
\hline $\mathrm{BB}(\mathrm{n}, \%)$ & $4585 \%$ & $7290 \%$ & 0.376 \\
\hline AMR (n, \%) & $4279 \%$ & $7087 \%$ & 0.272 \\
\hline
\end{tabular}

Notes: HR - heart rate; SBP - systolic blood pressure; LVEF - left ventricular ejection fraction; NYHA - New York Heart Association; ACE inhibitors - angiotensin-converting-enzyme inhibitor; ARB - angiotensin receptor blocker; BB - beta-blockers; AMR - antagonists of mineralocorticoid receptors 
We compared and analyzed the survival curves of patients depending on the above-mentioned indicators of kidney function. The average follow-up period was 13.4 months, the maximum was 27.5 months.

It turned out that a group of patients with RD had a significantly worse survival prognosis compared to a group without RD (Fig. 1). After adjusting the groups by age and the NYHA class, the difference was maintained (Fig. 2).

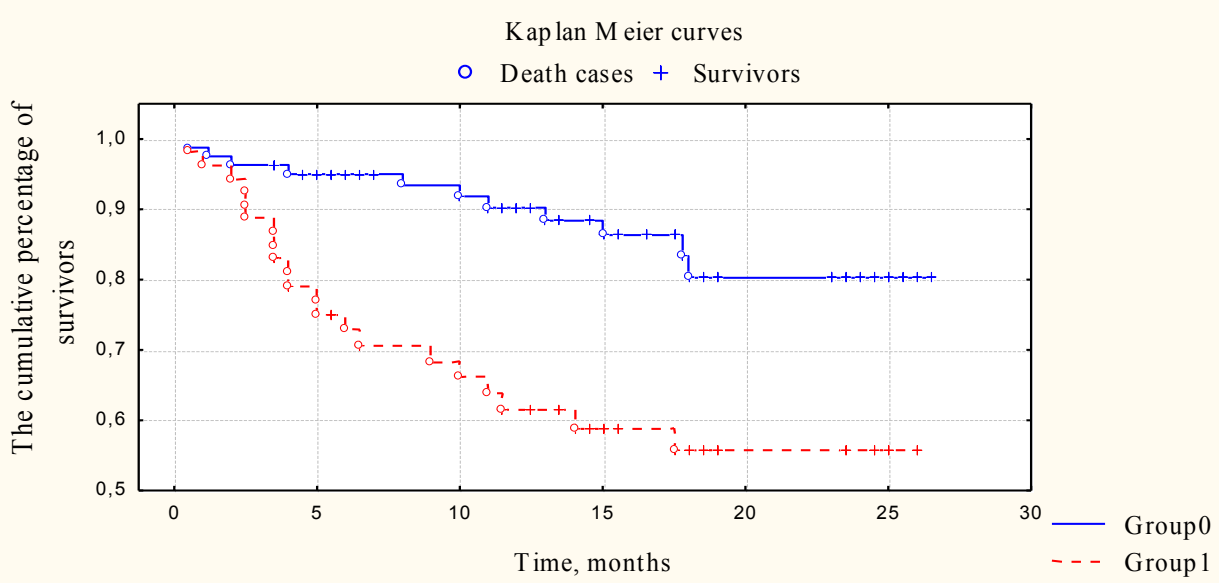

Fig. 1. Survival curves of patients with CHF and reduced LVEF depending on the level of GFR, $\mathrm{n}=134 ; \mathrm{p}=0.00065$; group $0-\mathrm{GFR}<60 \mathrm{ml} / \mathrm{min} / 1.73 \mathrm{~m}^{2}$; group $1-\mathrm{GFR} \geq 60 \mathrm{ml} / \mathrm{min} / 1.73 \mathrm{~m}^{2}$

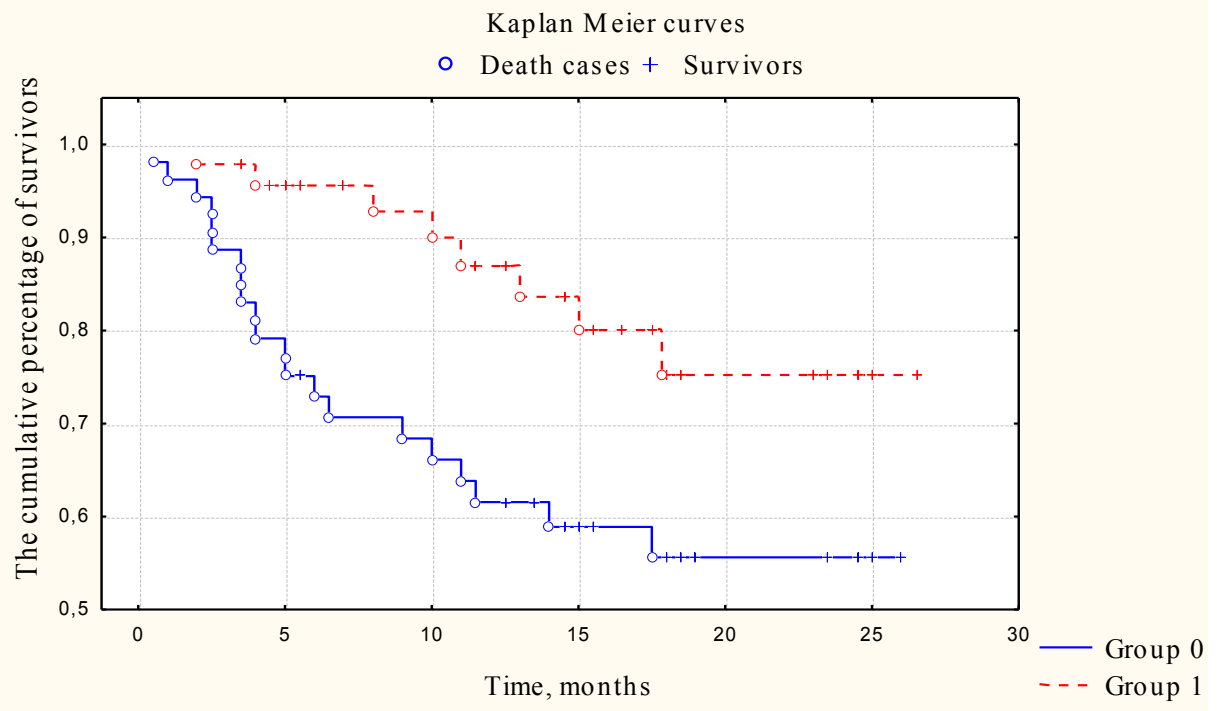

Fig. 2. Survival curves of groups of patients with $\mathrm{CHF}$ and reduced LVEF with and without RD, age-adjusted and NYHA class, $n=99, \mathrm{p}=0.014$, adjusted; group $0-\mathrm{GFR}<60 \mathrm{ml} / \mathrm{min} / 1.73 \mathrm{~m}^{2}$, group $1-\mathrm{GFR} \geq 60 \mathrm{ml} / \mathrm{min} / 1.73 \mathrm{~m}^{2}$

The groups of patients were formed depending on the median of BUN, the BUN/creatinine ratio, MAU, the albumin to creatinine ratio (ACR) to assess the prognostic value these indicators. It was found that the level of BUN did not significantly affect the prognosis of patients with CHF and reduced LVEF (Fig. 3).

At the same time, when the groups were divided, depending on the median value of the BUN/creatinine ratio, a significantly higher risk of fatal outcome was observed in the group with lower indices (Fig. 4). 


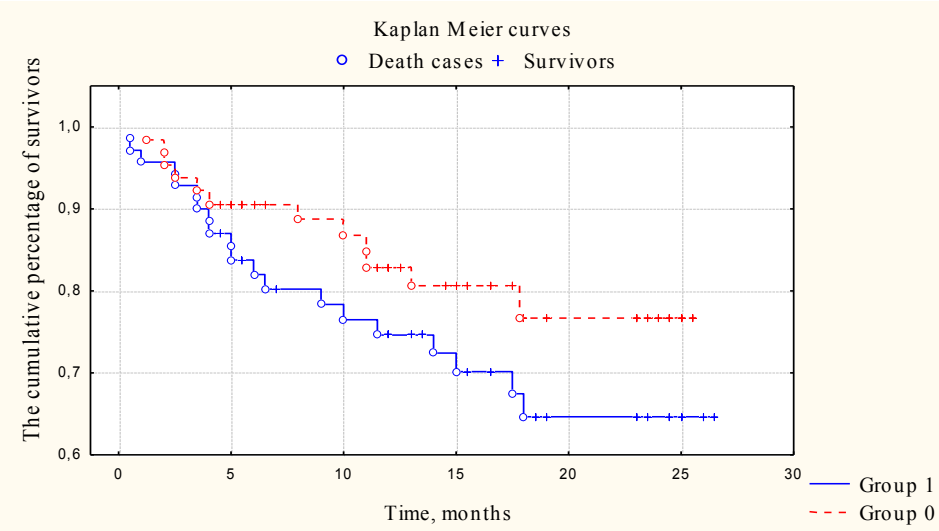

Fig. 3. Survival curves of patients with $\mathrm{CHF}$ and reduced LVEF, depending on the median plasma level of BUN, $\mathrm{n}=134, \mathrm{p}=0.176$; group 1 - BUN level $2.5 \mathrm{mmol} / \mathrm{l}$; group 0 - BUN level $<2.5 \mathrm{mmol} / 1$

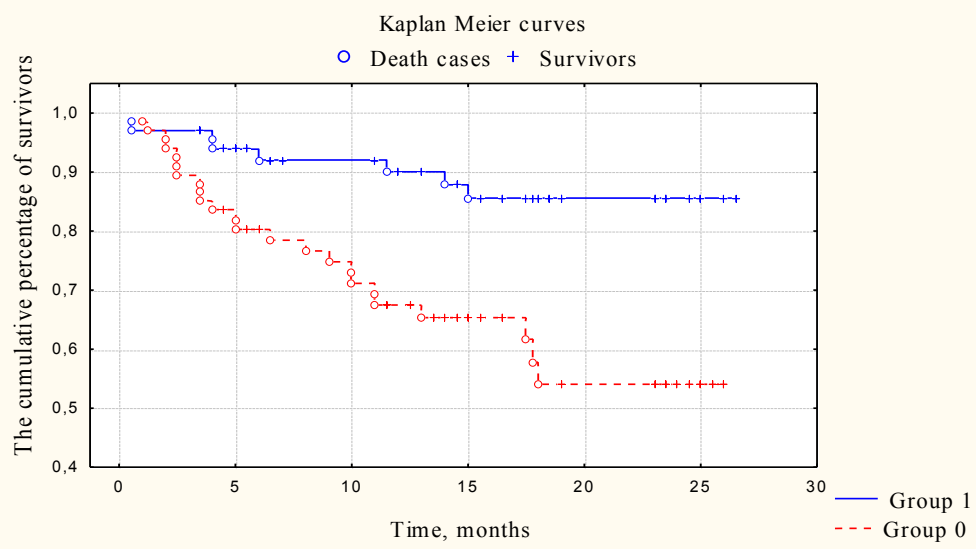

Fig. 4. Survival curves of patients with CHF and reduced LVEF, depending on the median of $\mathrm{BUN} /$ creatinine ratio in plasma, $\mathrm{n}=134, \mathrm{p}=0.0009$, group 1 - ratio of $\mathrm{BUN} /$ creatinine ratio in plasma $\geq 24.5$; group 0 - ratio of BUN/creatinine ratio in plasma $<24.5$

Among the examined MAU patients (29-300 mg/day) occurred in $94 \%$ of cases. The level of MAU did not significantly affect their survival (Fig. 5).

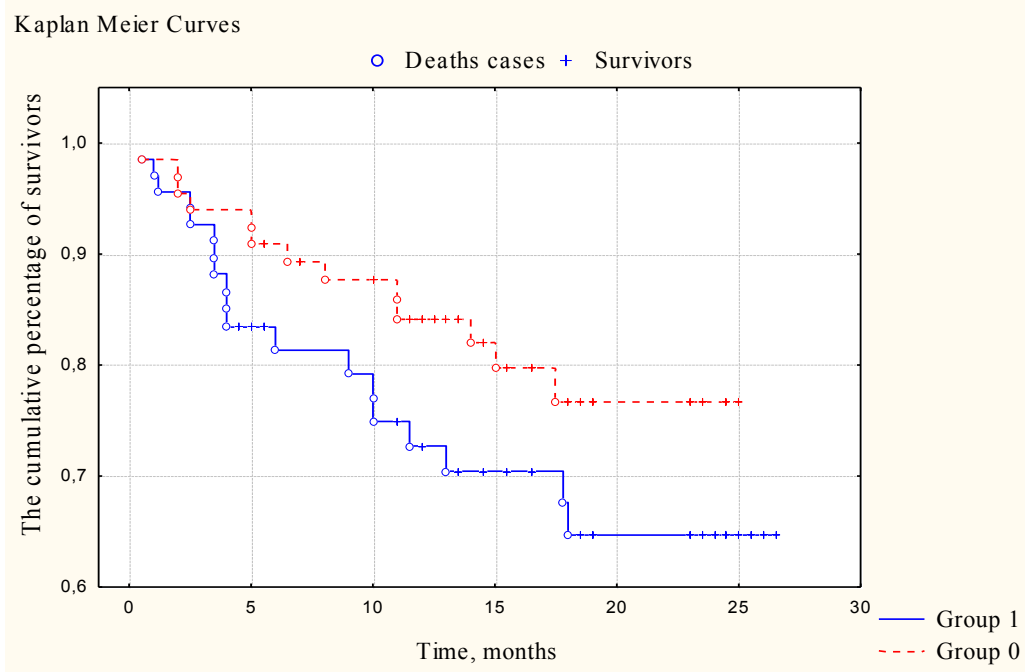

Fig. 5. Survival curves of patients with CHF and reduced LVEF, depending on the median of the MAU level, $\mathrm{n}=127$; $\mathrm{p}=0.147$; group 1 - level of MAU>104 mg/day; group 0 - level of $\mathrm{MAU}<104 \mathrm{mg} / \mathrm{day}$ 
In addition, a comparison of the survival of patients with higher and lower ACR revealed a significantly higher risk of death in patients with higher values (Fig. 6).

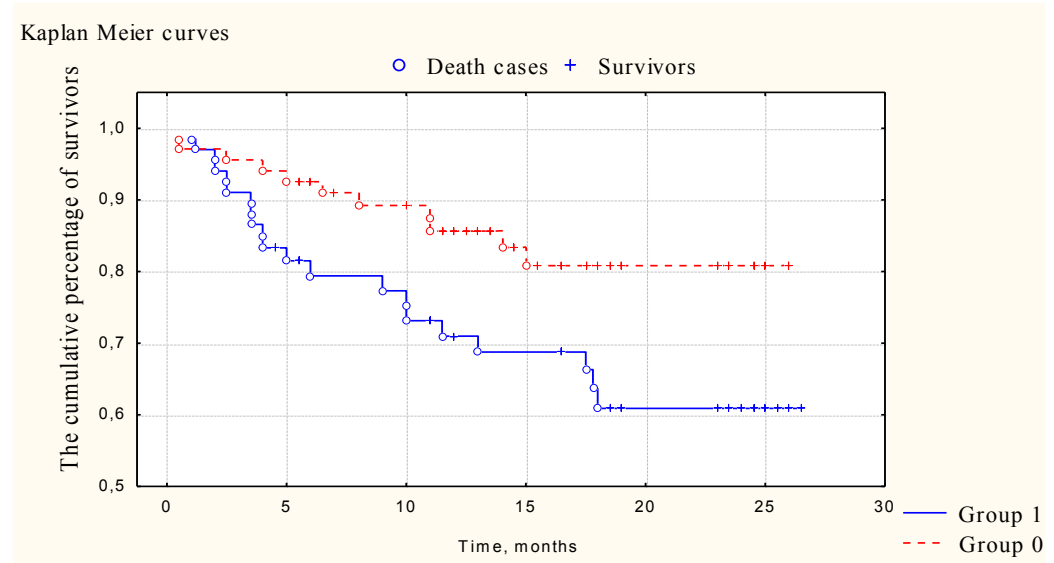

Fig. 6. Survival curves of patients with CHF and reduced LVEF, depending on the median of ACR, $n=134 ; p=0.028$; group $1-A C R \geq 12.72 \mathrm{mg} / \mathrm{mmol}$, group $0-\mathrm{ACR}<12.72 \mathrm{mg} / \mathrm{mmol}$

\section{Discussion}

The study confirmed, on the one hand, the high prevalence (almost $40 \%$ ) among patients with CHF and reduced LVEF, and on the other hand, the high prognostic significance of low GFR $<60 \mathrm{ml} / \mathrm{min} / 1.73 \mathrm{~m}^{2}$ in this category of patients $[4,16]$.

At the same time, we were not able to confirm the prognostic significance of BUN for longterm survival of such patients [17]. Nevertheless, the analysis of the BUN / creatinine ratio demonstrated its corresponding high informative value [18]. It is known that both BUN and creatinine are freely filtered in the glomerulus of the kidneys, while a part of BUN is reabsorbed under the action of vasopressin through the V2 receptors in the proximal tubules [10]. Thus, BUN reflects not only the function of glomeruls and tubules, but indirectly indicates the severity of neurohumoral activation, which in patients with CHF is most pronounced in a state of decompensation [19, 20]. Our patients had standard therapy with neurohumoral antagonists and were in the euvolemic state, which may explain the insufficient prognostic information level of BUN as such. An increase in the predictive informative value of the last indicator of such a component, which reflects the filtration status of the kidneys in the form of BUN / creatinine ratio, allowed to statistically reliably separate patients with the worst and best prognosis, which indicates the expediency of further study of this marker with stable CHF.

The study showed an almost total (94\%) prevalence of MAU in the surveyed, which is higher than that found in a similar category of patients by other authors [21, 22]. The explanation for the discrepancy may be the high prevalence of hypertension and diabetes mellitus ( $83 \%$ and $42 \%$, respectively) among our patients. It is known that the presence of MAU displays an increase in the permeability of the glomerular membrane due to its damage by increased hemodynamic load and endothelial dysfunction [23]. Nevertheless, the trend toward a higher risk of death in a group of patients with large MAU values has not been statistically confirmed. However, the approach that allows to compare the levels of albumin and creatinine excreted in the urine was more informative about the stratification of the long-term risk of death, which requires confirmation by further studies.

\section{Conclusions}

1. The presence of $\mathrm{RD}\left(\mathrm{GFR}<60 \mathrm{ml} / \mathrm{min} / 1.73 \mathrm{~m}^{2}\right)$ is observed in $39.5 \%$ of patients with $\mathrm{CHF}$ and reduced LVEF and is associated with their worst long-term survival.

2. Levels of BUN and MAU do not have sufficient predictive information about the forecast of long-term survival of the above category of patients.

3. At the same time, the values of the BUN/Creatinine ratio $<24.5$ and the ACR $>12.7$ indicate patients with CHF who have a higher long-term risk of death. 


\section{References}

[1] Savarese, G., Lund, L. H. (2017). Global Public Health Burden of Heart Failure. Cardiac Failure Review, 3 (1), 7-11. doi: http://doi.org/10.15420/cfr.2016:25:2

[2] Mozaffarian, D., Benjamin, E. J., Go, A. S., Arnett, D. K., Blaha, M. J., Cushman, M. et. al. (2014). Heart Disease and Stroke Statistics-2015 Update. Circulation, 131 (4), 29-322. doi: http:// doi.org/10.1161/cir.0000000000000152

[3] Crespo-Leiro, M. G., Anker, S. D., Maggioni, A. P., Coats, A. J., Filippatos, G. et. al. (2016). European Society of Cardiology Heart Failure Long-Term Registry (ESC-HF-LT): 1-year follow-up outcomes and differences across regions. European Journal of Heart Failure, 18 (6), 613-625. doi: http://oi. org/10.1002/ejhf.566

[4] Damman, K., Valente, M. A. E., Voors, A. A., O'Connor, C. M., van Veldhuisen, D. J., Hillege, H. L. (2013). Renal impairment, worsening renal function, and outcome in patients with heart failure: an updated meta-analysis. European Heart Journal, 35 (7), 455-469. doi: http://doi.org/10.1093/eurheartj/eht386

[5] Go, A. S., Chertow, G. M., Fan, D., McCulloch, C. E., Hsu, C. (2004). Chronic Kidney Disease and the Risks of Death, Cardiovascular Events, and Hospitalization. New England Journal of Medicine, 351 (13), 1296-1305. doi: http://doi.org/10.1056/nejmoa041031

[6] Ronco, C., Haapio, M., House, A. A., Anavekar, N., Bellomo, R. (2008). Cardiorenal Syndrome. Journal of the American College of Cardiology, 52 (19), 1527-1539. doi: http://doi.org/10.1016/ j.jacc.2008.07.051

[7] Zamora, E., Lupon, J., Vila, J., Urrutia, A., de Antonio, M., Sanz, H. et. al. (2012). Estimated Glomerular Filtration Rate and Prognosis in Heart Failure. Journal of the American College of Cardiology, 59 (19), 1709-1715. doi: http://doi.org/10.1016/j.jacc.2011.11.066

[8] Kidney Disease: Improving Global Outcomes (KDIGO) CKD Work Group. KDIGO (2012). Clinical Practice Disease. Kidney inter, 1-150.

[9] Hillege, H. L., Girbes, A. R. J., de Kam, P. J., Boomsma, F., de Zeeuw, D., Charlesworth, A. et. al. (2000). Renal Function, Neurohormonal Activation, and Survival in Patients With Chronic Heart Failure. Circulation, 102 (2), 203-210. doi: http://doi.org/10.1161/01.cir.102.2.203

[10] Schrier, R. W. (2008). Blood Urea Nitrogen and Serum Creatinine: Not Married in Heart Failure. Circulation: Heart Failure, 1 (1), 2-5. doi: http://doi.org/10.1161/circheartfailure.108.770834

[11] Ivanov, D. D. (2005). Khronichna khvoroba nyrok. Mizhnarodnyi endokrynolohichnyi zhurnal, 2, 67-72. Available at: http://www.mif-ua.com/archive/article/2255

[12] Dahlöf, B., Devereux, R. B., Kjeldsen, S. E., Julius, S., Beevers, G., de Faire, U. et. al. (2002). Cardiovascular morbidity and mortality in the Losartan Intervention For Endpoint reduction in hypertension study (LIFE): a randomised trial against atenolol. The Lancet, 359 (9311), 995-1003. doi: http:// doi.org/10.1016/s0140-6736(02)08089-3

[13] Zima, T. (2002). Laboratorna diagnostika. Galen, 1146.

[14] Medcalf, E., Newman, D., Gorman, E., Price, C. (1999). Rapid, Robust method for measuring low concentration of albumin in urine. Clin Chem, 3, 446-449. Available at: https://www.ncbi.nlm.nih.gov/ pubmed/2311211

[15] Voronkov, L. H. et. al. (Eds.) (2017). Rekomendatsii Asotsiatsii kardiolohiv Ukrainy z diahnostyky ta likuvannia khronichnoi sertsevoi nedostatnosti. Kyiv. Available at: http://health-ua.com/multimedia/3/6/4/9/1/1524039163.pdf

[16] Damman, K., Testani, J. M. (2015). The kidney in heart failure: an update. European Heart Journal, 36 (23), 1437-1444. doi: http://doi.org/10.1093/eurheartj/ehv010

[17] Van Veldhuisen, D. J., Ruilope, L. M., Maisel, A. S., Damman, K. (2015). Biomarkers of renal injury and function: diagnostic, prognostic and therapeutic implications in heart failure. European Heart Journal, 37 (33), 2577-2585. doi: http://doi.org/10.1093/eurheartj/ehv588

[18] Parrinello, G., Torres, D., Testani, J. M., Almasio, P. L., Bellanca, M., Pizzo, G. et. al. (2015). Blood urea nitrogen to creatinine ratio is associated with congestion and mortality in heart failure patients with renal dysfunction. Internal and Emergency Medicine, 10 (8), 965-972. doi: http://doi.org/10.1007/s11739015-1261-1

[19] Palazzuoli, A., Ruocco, G., Pellegrini, M., Martini, S., Del Castillo, G., Beltrami, M. et. al. (2014). Patients with Cardiorenal Syndrome Revealed Increased Neurohormonal Activity, Tubular and Myo- 
cardial Damage Compared to Heart Failure Patients with Preserved Renal Function. Cardiorenal Medicine, 4 (3-4), 257-268. doi: http://doi.org/10.1159/000368375

[20] Abraham, W. T., Shrier, R. W. (1996). Renal salt and Water Handling in Congestive heart Failure. Congestive Heart Failure. New York: Springer-Verland, 161-173.

[21] Jackson, C. E., Solomon, S. D., Gerstein, H. C., Zetterstrand, S., Olofsson, B., Michelson, E. L. et. al. (2009). Albuminuria in chronic heart failure: prevalence and prognostic importance. The Lancet, 374 (9689), 543-550. doi: http://doi.org/10.1016/s0140-6736(09)61378-7

[22] Metra, M., Cotter, G., Gheorghiade, M., Dei Cas, L., Voors, A. A. (2012). The role of the kidney in heart failure. European Heart Journal, 33 (17), 2135-2142. doi: http://doi.org/10.1093/eurheartj/ehs205

[23] Sirenko, Yu. M. (2010). Novi mozhlyvosti vyznachennia mikroalbuminurii v klinichnii praktytsi. Arterrialna hipertenziia, 3 (11), 55-57. Available at: http://www.mif-ua.com/archive/article/13069

\title{
ROLE OF THE PERICARDIOSCOPY IN THE TREATMENT OF PERICARDIAL EFFUSION
}

\author{
Yulia Pisklova \\ Department of Cardiac Surgery \\ Zaycev V. T. Institute of General and Urgent Surgery NAMS of Ukraine \\ 1 Balakireva entr., Kharkiv, Ukraine, 61018 \\ yuliapisklova@gmail.com
}

\begin{abstract}
In recent years surgical treatment of pericardial effusion has been favoured by mini-invasive interventions. Pericardioscopy supplements it. In the literature actively discusses its expediency, efficiency and informativeness.

Aim of the study. Analyze our experience of using pericardioscopy during surgical treatment of pericardial effusion using mini-invasive interventions.

Materials and methods. From 2000 to 2017, 92 patients with pericardial effusion were operated in our clinic using mini-invasive interventions. Pericardioscopy was used in 72 (78.26 \%) cases. In 32 (44.44\%) pericardioscopy was performed with subxiphoid pericardiotomy, in 40 (55.56\%) - with thoracoscopy on the right or left side.

Results and discussion. The use of pericardioscopy has allowed to significantly reduce the number of idiopathic pericarditis from $20.0 \%$ to $5.56 \%$ and increase the informativeness of the minimally invasive interventions by $14.44 \%\left(\chi^{2}=4.11\right.$, with $v=1$, $\alpha=5 \%$ ). There is no reliable difference in the number of relapses of the disease.

Conclusions. The use of pericardioscopy during mini-invasive interventions is safe and effective. The method of choice in most cases is subxiphoid non-pleural pericardiotomy with pericardioscopy.

Keywords: pericarditis, pericardioscopy, surgical treatment, minimally invasive.
\end{abstract}

\section{Introduction}

In recent years, the incidence of pericarditis has been rising steadily. The reason for this, according to many authors, is the development of diagnostic and therapeutic technologies and the deterioration of the quality of life of the population $[1,2]$. The most common pericardial pathology is exudative pericarditis of different etiologies. Cases of the initial occurrence of effusion in the pericardium cavity are singular [3, 4]. Their cause in the vast majority are various infectious (viral and bacterial), systemic, autoimmune, neoplasm diseases, injuries, heart disease and pericardium, etc. $[5,6]$. At the same time, to find out the cause of the disease can not always be possible and then they speak about the idiopathic nature of the disease [7, 8]. A large number of idiomatic exudative pericarditis is an urgent and debatable problem, because without identifying and eliminating the root cause, the risk of chronic and recurrent pericardial inflammation is significantly increased $[1,9]$. The level of mortality from exudative pericarditis depends on many factors, including the etiology, the prescription of the process, the severity of the underlying disease and related disorders, 